\title{
ENSINO DE HISTÓRIA: \\ NA BUSCA DE NOVAS ATUAÇÕES, ABORDAGENS E \\ PERSPECTIVAS
}

\author{
TEACHING OF HISTORY: \\ THE SEARCH FOR NEW ACTIONS, APPROACHES AND PERSPECTIVES
}

Josiane Alves da Silveira ${ }^{1}$

\begin{abstract}
RESUMO: Trata sobre o ensino de História, levando-se em conta o estágio de desenvolvimento cognitivo dos alunos e a ligação da História com a realidade desses alunos. Dessa forma, busca analisar os conteúdos e as metodologias utilizados no ensino de História, principalmente no $6^{\circ}$ ano do ensino fundamental. Para tanto, utilizando a metodologia da História Oral, realiza entrevistas com quatro professoras da área, em escolas públicas da cidade do Rio Grande (RS), sendo duas da rede estadual e as outras duas da rede municipal. Aponta como questionamento a necessidade do aprofundamento reflexivo a respeito dos conteúdos e das metodologias de ensino empregadas na atualidade. Conclui que, devido à maior dificuldade de abstração dos alunos no $6^{\circ}$ ano, o professor pode facilitar a aprendizagem se propor atividades que relacionem o conteúdo com a atualidade e o cotidiano dos alunos, possibilitando o maior envolvimento destes com a História.
\end{abstract}

Palavras-chave: Ensino de História. Conteúdos. Metodologias. Ensino fundamental.

\begin{abstract}
This is about the teaching of history, taking into account the stage of cognitive development of students and connection of history with the reality of these students. It also tries to analyze the content and the methodologies used in teaching history, especially in the 6th grade of elementary school. For this purpose, using the methodology of oral history, conducts interviews with four teachers in the area, in public schools in Rio Grande (RS), two of the state and the other two in the municipal. Indicates how questioning the need for deepening reflection about the content and teaching methodologies employed in the present. Concluded that due to the greater difficulty of abstraction of students in 6th grade, the teacher can facilitate learning to propose activities that relate to current content and the daily lives of students, allowing greater involvement these with history.
\end{abstract}

Keywords: Teaching of History. Content. Methodologies. Elementary school.

\section{Introdução}

\footnotetext{
1 Mestranda em Educação pelo Programa de Pós-Graduação em Educação da Universidade Federal de Pelotas (UFPel).
}

História \& Ensino, Londrina, v. 18, n. 2, p. 203-232, jul./dez. 2012 
O presente trabalho tem como foco o ensino de História, principalmente, no $6^{\circ}$ ano do ensino fundamental público. Esse tema surgiu da necessidade de se verificar a aprendizagem dos conteúdos históricos nessa etapa de ensino, levando-se em conta o estágio de desenvolvimento cognitivo dos alunos. Isto porque os tempos históricos do conteúdo oficial do $6^{\circ}$ ano, a História Antiga, envolvem uma maior capacidade de abstração, o que pode ser um obstáculo na aprendizagem de alunos com idade regular entre 10 a 11 anos. Sabe-se que, em conformidade com a teoria piagetiana, nessa faixa etária o discente exerce melhor suas capacidades a partir de objetos concretos.

Além disso, novas abordagens sobre o ensino de História desapegadas da História tradicional que privilegia os grandes acontecimentos de personagens heroicos em datas marcantes - revelam que os conteúdos históricos que não estiverem alinhavados com a atualidade podem dificultar a compreensão do aluno, impossibilitando-o de sentir-se como agente dessa História. A nova tendência privilegia uma "História viva", ou seja, uma História que desperte no aluno a curiosidade para conhecer a sua vida, a realidade que o rodeia, ligando o presente ao passado. Indo ao encontro de tal tendência, verifica-se nesse trabalho qual abordagem destaca-se no atual ensino de História.

Por tudo, torna-se importante pesquisar, mesmo que parcialmente, como se encaminha o ensino de História no $6^{\circ}$ ano. Para tanto, são apresentados alguns recortes das entrevistas realizadas com quatro professoras da área, na cidade do Rio Grande, estado do Rio Grande do Sul (RS), no ano de 2008. Essas entrevistas foram realizadas nas escolas onde as professoras lecionavam, ou seja, a professora Eliane Fialho Rosa, na Escola Estadual de Ensino Médio Bibiano de Almeida; a professora Regina Quiroga Neves, na Escola Municipal de Ensino Fundamental Helena Small; a professora Rosangela Meireles Costa, na Escola Municipal de Ensino Fundamental Clemente Pinto; e a professora Maria Luiza Tavares Ferreira, na Escola Estadual de Ensino Fundamental Marechal Emílio Luiz Mallet².

\footnotetext{
2 A escolha por escolas localizadas no centro e em bairros do Rio Grande tem por objetivo não restringir a pesquisa a uma área da cidade, buscando com isso conhecer as diferentes realidades das escolas públicas.
} 
Baseadas na metodologia de História Oral, as entrevistas temáticas seguiram um roteiro com questões voltadas para o conteúdo programático de História, os recursos didáticos e, por fim, abriu-se um espaço de reflexão sobre a entrevista. A partir dos relatos foi possível tecer algumas considerações entre as informações destacadas pelas professoras e o ensino de História. Assim, busca-se ressaltar a importância de um ensino que responda às expectativas dos alunos e contribua para uma formação humanística dos atores envolvidos no processo de ensino-aprendizagem.

Assim, a pesquisa torna-se importante porque pretende verificar, por um lado, como a História está sendo ensinada no $6^{\circ}$ ano e, por outro, a importância de outras formas de ensinar História que não perpetuem os mitos da memória dominante. Além de tudo, a pesquisa apresenta relevância porque propõe a partir da reflexão, a divulgação dos resultados da pesquisa, buscando suprir a carência de estudo na área.

O presente trabalho foi dividido em três partes. As duas primeiras partes destacam o ensino de História, apresentando como foco central a difícil abstração de certos conteúdos de História e os métodos utilizados pelos professores para facilitar a aprendizagem dos alunos no ensino fundamental. Por fim, a última parte apresenta a pesquisa realizada nas quatro escolas públicas do Rio Grande, destacando as entrevistas com as professoras de História e tecendo considerações a respeito do ensino de História.

\section{Construindo bases para o ensino-aprendizagem de História no ensino fundamental}

Trabalhos sobre a teoria piagetiana revelaram que os conteúdos históricos que envolvem uma maior capacidade de abstração acabam sendo um problema para alunos entre 7 a 11 ou 12 anos de idade. Isto porque nessa fase os alunos conseguem exercer melhor suas habilidades e capacidades a partir de objetos reais, concretos. Por isso, neste trabalho apresenta-se uma reflexão sobre os critérios de construção do conhecimento histórico pelos alunos, nas séries iniciais. Esses primeiros 
passos são fundamentais para o aluno progredir em seu ritmo, cabendo ao professor dar assistência para facilitar a aprendizagem, através de conteúdos e métodos adequados.

Com bem destaca Mizukami (1986, p. 63-64), na abordagem cognitiva o "[...] conhecimento é considerado como uma construção continua. A passagem de um estado de desenvolvimento para o seguinte é sempre caracterizada por formação de novas estruturas que não existiam anteriormente no indivíduo". Para facilitar esse desenvolvimento, o professor de História deve provocar o "desequilíbrio" no aluno, ou seja, propor atividades desafiadoras aos alunos para facilitar a passagem do pensamento concreto para o formal, abstrato. A partir de então, o aluno terá condições de compreender melhor os conteúdos históricos, facilitando a aprendizagem da disciplina de História no ensino fundamental.

Antes de se discutir sobre o ensino de História, principal objetivo neste estudo, torna-se necessário recapitular a importância da construção de uma base sólida de aprendizagem nas séries iniciais. Até porque esse é o momento em que o aluno dá os seus primeiros passos em busca de um ensino sistematizado. Como bem destaca Penteado

É, pois, nestas séries iniciais que um conhecimento básico em termos de conteúdos (aprendizagem de conteúdos básicos) e de habilidades (procedimentos de observação, comparação, registro de representações espaciais e temporais, iniciação em leitura de mapas e globos, resolução de problemas) tem de ser desenvolvido (PENTEADO, 1991, p. 12).

Porém, aspectos relacionados com o tempo histórico são abstratos e, por isso, podem dificultar a compreensão dos alunos nas séries iniciais. É o que destaca Carretero (1997, p. 15) em suas pesquisas e ao enfatizar que estudos realizados por Piaget revelaram "que as crianças tinham claras dificuldades para entender os conteúdos históricos devido às limitações gerais impostas pelo seu desenvolvimento cognitivo". Observou-se que alunos das séries iniciais não compreendem a complexidade dos conteúdos históricos, por isso considera-se importante uma aprendizagem significativa nos primeiros anos de aprendizagem.

É importante destacar que a construção de bases para uma verdadeira aprendizagem deve considerar o amadurecimento das diversas 
fases psicológicas. Isto porque "por suas próprias características de desenvolvimento mental, antes dos 11-12 anos a criança não tem condições de compreender o tempo histórico, porque ela não consegue analisar realidades distantes e objetos fora do presente" (CALLAI, 1991, p. 57). Portanto, se nas séries iniciais tais questões não forem bem trabalhadas, provavelmente os alunos terão maiores dificuldades no decorrer dos próximos anos do ensino fundamental.

Por isso, como ressalta Neves (1985, p. 6), torna-se fundamental realizar um "teste de sondagem" para avaliar o grau de desenvolvimento da percepção espaço-temporal que os alunos possuem. O resultado dessa sondagem deve levar o professor a seguir o conteúdo ou, se for o caso, reforçar o que ainda não foi assimilado pelo aluno. É o que destaca Penteado a seguir:

As defasagens de aprendizagem entre os alunos freqüentemente são atribuídas à escolaridade anterior. Esse diagnóstico é importante se, e somente se, utilizado para refazer o que for necessário, fazer o que ainda não foi feito e prosseguir com segurança na programação proposta (PENTEADO, 1991, p. 76).

Dessa forma, destaca-se que a aprendizagem a partir da vida do aluno mostra-se um caminho coerente. Nas séries iniciais a aprendizagem básica pode fazer com que o aluno compreenda o seu "viver", ou seja, compreenda a sociedade em que vive, conhecendo o espaço que está sendo construído por essa sociedade e o tempo em que vivem. Sendo que, tanto o espaço construído como o tempo vivenciado, reflete um passado e ao mesmo tempo fecundam um futuro (CALLAI, 1991, p. 39).

Destaca Enderle (1985, p. 79), que antes dos 12 anos "não existem condições de absorver as noções de um universo abstrato e complexo porque está em vigência a assimilação da objetividade, do concreto, ou seja, a assimilação do mundo real". E, conforme Nidelcoff:

Mesmo que antes dos 11 anos, já estejam bem aptas para lidar com relações de ordem temporal ("antes - "depois") e com durações (mais ou menos tempo), as crianças não estão em condições de levar esses conceitos para um tempo tão distante de sua experiência como o tempo histórico... Elas se 
exercitam comodamente na vida cotidiana (NIDELCOFF, 1993, p. 81-82).

Ainda, para Nidelcoff (1993) a História ensinada antes dos 14 anos deve ser descritiva, pois os alunos podem compreender como se vivia em uma determinada época, mas pode estar acima de suas possibilidades compreenderem algumas causas e explicações. Isto porque, "o mundo das instituições e das complicadas organizações políticas está distante do interesse das crianças" (NIDELCOFF, 1993, p. 83).

Apoiando-se na teoria piagetiana, Nidelcoff (1993) destaca que o aprendizado da História não deveria começar antes dos 11 ou 12 anos, momento de cristalização do pensamento formal, e mesmo depois dessa fase, deve-se ter muito cuidado. Isto porque, as crianças encontram dificuldades no aprendizado da História, primeiramente porque enfrentam o problema da percepção do tempo e, em seguida, porque os temas não coincidem com o interesse e as possibilidades de compreensão das crianças.

Carretero (1997, p. 32) também esclarece que pesquisas apoiadas na teoria de Piaget sugeriam que se retardasse a introdução da História na escola, buscando adaptar o currículo ao processo de desenvolvimento cognitivo do aluno. Porém, não houve evidências suficientes que confirmassem essas pesquisas como apropriadas.

A teoria de Piaget foi criticada por Vygotsky que não concordava com a possibilidade de existir uma sequência de estágios cognitivos. Isto porque, para Vygotsky a interação social seria fator essencial para a evolução da aprendizagem dos seres humanos. Já Piaget considerava a maturação biológica mais importante do que a interação social. Segundo Bock, para Vygotsky:

A aprendizagem é [...] um processo essencialmente social, que ocorre na interação com adultos e os colegas. O desenvolvimento é resultado desse processo, e a escola, o lugar privilegiado para essa estimulação. A educação passa, então a ser como processo social sistemático de construção da humanidade (BOCK, 2002, p. 126).

Assim, acredita-se que inúmeras interferências socioculturais da vida cotidiana forçam os alunos a resolverem problemas, reequilibrando 0 
processo cognitivo que pode atingir níveis nem sempre dentro da faixa etária prevista. É o que destaca Bittencourt a seguir:

A eficiência do ensino está comprometida com o nível de desenvolvimento do aluno, sem esquecer o desenvolvimento operatório piagetiano, mas encontra-se relacionada às estruturas de conhecimento adquiridas por uma série de experiências e formas de convívio que incluem motivações e emoções (BITTENCOURT, 2004, p. 189).

Bittencourt (2004, p. 196-197), citando outros autores, também destaca algumas críticas à teoria piagetiana. Segundo a autora, a teoria piagetiana serviu para impedir o ensino de História para alunos de determinadas faixas etárias. Isso buscou fazer da disciplina um saber secundário, cujo insucesso estaria relacionado à incapacidade cognitiva dos alunos de dominar conceitos e conteúdos.

Enfim, acredita-se que reconhecer tanto o conhecimento prévio do aluno, adquirido da sua interação social, como às fases do desenvolvimento cognitivo são importantes e indispensáveis para promover uma aprendizagem significativa. Esses conhecimentos não podem ser desconsiderados. Muito pelo contrário, as experiências dos alunos devem ser exploradas no cotidiano escolar, assim como devem ser reconhecidos os limites de desenvolvimento de cada criança, buscando sempre ultrapassálos na tentativa de aprimorar a aprendizagem. O professor, como mediador entre as condições internas e externas de aprendizagem, deve levar em conta as características de pensamento do aluno, anterior à fase do raciocínio formal e abstrato.

Portanto, cabe ao professor o desafio de saber conduzir o conhecimento histórico do aluno e aprimorar a sua capacidade cognitiva dentro das atividades de aprendizagem de História. Isto porque a partir do conhecimento sistematizado nas séries iniciais, o aluno terá melhores possibilidades de adaptação e compreensão da História nas séries seguintes. Principalmente, a partir do $6^{\circ}$ ano do ensino fundamental quando o aluno se depara com uma nova estrutura de aprendizagem, incluindo novos conteúdos e professores.

\section{Alguns conteúdos e procedimentos que promovam o ensino- aprendizagem de História}


As dificuldades encontradas no ensino de História podem residir tanto no conteúdo selecionado como nos procedimentos com que são trabalhados. Para superar esse fatalismo, torna-se necessário buscar a compreensão da realidade do aluno; despertar a curiosidade dele em relação ao conteúdo e, ainda desenvolver nele instrumentos de conhecimento da sua vida a partir do ensino de História. O professor pode apresentar uma "História viva" para os alunos e não uma coletânea de fatos passados sem nenhuma relação com o presente.

Como bem destaca Bergamaschi

\begin{abstract}
A partir do momento em que a História passa a ser ensinada como uma disciplina, o cenário predominante na maioria dos programas escolares é a transmissão de longos e enfadonhos conteúdos, que pretendem abordar desde tempos préhistóricos até os nossos dias, em que nem esse "longo tempo", estudado de forma periodizada, é alvo de questionamento (BERGAMASCHI, 2000, p. 40).
\end{abstract}

No entanto, como critério de seleção dos conteúdos principais, o professor não deveria se preocupar simplesmente com a memorização de muitos dados, mas que os alunos saibam refletir e analisar de maneira profunda elementos que os auxiliem na compreensão da vida do homem. Porém, segundo Lück (2007, p. 21), "os professores, no esforço de levar seus alunos a aprender, o fazem de maneira a dar importância ao conteúdo em si e não à sua interligação com a situação da qual emerge, gerando a já clássica dissociação entre teoria e prática".

O professor deve estar consciente de que não esgota na escola o processo de conhecimento, mas introduz o aluno nessa questão. 0 importante é que essa introdução seja significativa, carregada de sentido para o aluno. Acrescenta Penteado (1991, p. 160): "Não cabe ao professor e à escola saciar a curiosidade, mas sim alimentá-la, deixando instrumentos com o aluno que lhe possibilitem ser, cada vez mais, indagativo, reflexivo. Assim estará inserido no caminho do ser criativo e transformador".

Da mesma forma, o professor não deve priorizar o estudo de todas as datas históricas, mas as principais que localizem os alunos no tempo. É importante que os alunos conheçam datas-chave que lhes sirvam de referência para situar o fato dentro de um período. Ressalta Nidelcoff 
(1993, p. 56): "Quando tratarmos do aprendizado da História, veremos que também aí é necessário que a criança tenha como esquema de referência uma 'coleção' de datas muito importante. O que de nenhuma maneira implica em dar uma importância preponderante à memorização".

Cabe ao professor dar sentido às datações, para que o aluno domine algumas datas principais como pontos referenciais para o entendimento dos acontecimentos históricos. Diz Bittencourt (2004, p. 211): "apenas conhecer datas e memorizá-las, como se sabe, não constitui um aprendizado significativo, a não ser que se entenda o sentido das datações". Nesse sentido, também vale situar o aluno na associação entre o século e o tema em estudo. Porém, não raro os alunos do ensino fundamental têm dificuldades de fazer tal associação, o que reafirma a necessidade do professor realizar constantemente o "teste de sondagem" em sala de aula.

O domínio de conceitos básicos também é fundamental para assegurar a sistematização dos conteúdos. Segundo Carretero (1997, p. 3435 ), os conceitos históricos são fundamentais no processo de aprendizagem. Deve-se considerar que muitos conceitos possuem um nível de abstração elevado, ainda exigem a compreensão de outros conceitos e também são "mutantes", ou seja, não possuem um significado único ao longo da História. Daí a importância de saber que o conhecimento histórico passa pela mediação de conceitos. Sem esses conceitos o ensino de História torna-se inviável.

Propondo uma nova alternativa para o ensino de História, Neves $(1985$, p. 8) ressalta que "para romper com a periodização tradicional e, na seleção de conteúdos, afastar-se de fatos consagrados pela erudição e, em contrapartida, enfatizar aspectos da vida humana tradicionalmente menos considerados" o professor pode selecionar o cerne da História, o tempo, alterando a sua percepção, ou seja, acabar com a visão evolucionista, pautada no progresso, em um tempo linear (sem cortes ou retornos), contínuo e curto. Ainda, segue a autora, o professor precisa dar vida ao homem trabalhado na História. Para isso, deve

Fazer o aluno senti-lo no cotidiano, levá-lo perceber que, como ele, este homem enfrentava problemas para sobreviver e conviver. Concretizá-lo como um ser que necessitava 
alimentar-se, vestir-se, trabalhar, divertir-se; que ficava doente, amava, temia... Libertá-lo da aberração representada pela visão de um homem histórico, exclusivamente político, extremamente abstrato e distante para ele (NEVES, 1985, p. $8)$.

Isto porque, a História não deve ser vista como um passado-passado, importante apenas na composição da linha evolucionária da humanidade, mas como um passado-presente, que explique processos aparentemente contraditórios. Enfim, que conscientize o aluno da dialética entre a mudança e a permanência.

O professor de História poderá priorizar um conteúdo que "levará os alunos a se conhecerem através do conhecimento dos outros homens em geral: os homens da sua localidade, do seu tempo, de outras localidades, de outros tempos" (NIDELCOFF, 1993, p. 7). Para tanto, o professor pode instigar os alunos a conhecer e analisar a realidade que os rodeia, começando com o "estudo do meio" e, aos poucos, estendendo o olhar dos alunos para novos horizontes.

Da mesma forma, Miceli (1992, p. 34) propõe uma "história militante", onde estudo e vivência pudessem, de alguma forma, permanecer juntos. Segundo a autora, "a tarefa que se impõe é a de retificação radical da história tradicional que alimenta a memória coletiva" (MICELI, 1992, p. 34). Repensar a História requer repensar o sentido do próprio conhecimento, o que significa não somente a eleição de novos fatos ou acontecimentos, mas uma nova relação com esses e quaisquer outros fatos. Esclarece Miceli (1992, p. 34), "nenhum tema possui, em si, uma carga maior ou menor de 'historicidade'; é a relação que com ele estabelece quem o trabalha que pode ou não fazer dele um tema histórico".

Através do aprendizado da História os alunos podem compreender o presente, vendo o mundo como um longo processo. Isto justifica a presença e a importância da disciplina História na escola. Nesse sentido, destaca Nidelcoff:

A compreensão do mundo que nos rodeia e suas características, a procura de uma resposta às perguntas que a época atual nos apresenta, levam-nos sempre ao passado, à origem do processo que estamos observando e vivendo [...] não existe maneira de responder sem apelar para a História. Sua contribuição é insubstituível (NIDELCOFF, 1993, p. 68). 
Portanto, torna-se fundamental deixar de lado conteúdos que são fixados por hábito, mas que não trazem nenhuma contribuição para o entendimento do presente. Assim, o tempo gasto com conteúdo inadequado, pode ser utilizado para trabalhar com temas mais significantes na atualidade. Como destaca Nidelcoff:

Não basta ensinar "fatos que ocorreram no passado" para dar às crianças elementos para que compreendam o presente. Muitas maneiras erradas de dar História não se tornam apenas uma sucessão angustiante e inútil de nomes e datas, mas chegam a se tornar inibitórias para um enfoque posterior, mais inteligente, desses fatos (NIDELCOFF, 1993, p. 70).

Quanto aos métodos, os alunos precisam ver a História como algo vivo no presente. $\mathrm{E}$, cabe ao professor ajudar o aluno a ver essa vinculação. O exercício de vínculo com o presente deve ser permanente, comparando semelhanças ou diferenças, procurando no presente as consequências do passado e no passado à explicação do presente.

Para tanto, noções espaço-temporais ajudam o aluno a compreender a realidade vivida, por isso exercícios com mapas e linhas de tempo são identificados como primordiais para aprendizagem. Isto porque a linha de tempo além de envolver uma série de informações também oferece uma grande possibilidade de abstrações. Já o mapa pode servir como maneira de representar, decompor, analisar e recompor o espaço geográfico, enfim como instrumento auxiliar na construção do conceito de espaço. Portanto, torna-se necessário à realização de exercícios práticos e a teorização dessas atividades. Sobre isso, acrescenta Nidelcoff:

Não basta localizar no mapa onde estão a Mesopotâmia ou a Grécia; as crianças têm que compreender a vida de um povo no passado em relação a um determinado meio geográfico, que possibilita certos progressos em sua cultura e as limita em outros aspectos: o clima, a fertilidade ou a aridez das terras que permite uma ou outra forma de exploração econômica, a presença de bosques, de pedras, de metais, localização: isolado ou com muitas possibilidades de comunicação, etc. (NIDELCOFF, 1993, p. 77)

Porém, como bem ressalta Fonseca (2005, p. 46), "o peso da tradicional historiografia e a concepção de história de pais, alunos e muitos 
professores - identificada, muitas vezes, apenas como grandes feitos dos heróis - dificultam a incorporação de novos campos temáticos, de novos problemas e fontes", como enfatizam as novas correntes historiográficas. Mesmo assim, o esforço para superar as velhas barreiras do ensino tradicional deve ser constante.

Bergamaschi (2000) também destaca outra maneira de diversificar o ensino de História, utilizando-se de eixos temáticos. Para a autora, trabalhar com eixo temático significa "destacar um problema ou tema do cotidiano e que, partindo do presente vivido, refletido e sistematizado, busca a apreensão de outras realidades no tempo e no espaço, também a partir de um referencial que redimensiona a relação com o passado histórico" (BERGAMASCHI, 2000, p. 90).

Como já foi dito, os alunos levam para a escola suas experiências sociais. Então, torna-se importante propor na sala de aula uma atividade de levantamento ou problematização de situações vivenciadas pelos alunos. Atividades de leitura e compreensão de textos também podem ser sugeridas para posterior ligação com as vivências dos alunos. Dessa forma, - aluno terá oportunidade de aprofundar e reexaminar sua própria realidade. $^{3}$

Funari (2007, p. 101) cita algumas estratégias importantes em sala de aula. Para o autor, atividades com história em quadrinhos e palavras cruzadas, por exemplo, por mais triviais que possam parecer, são mais interessantes para o aluno e alcançam resultados muito melhores do que a simples memorização, sempre temporária de conteúdos.

Atividades que envolvam fontes ou documentos diversificados também são imprescindíveis, pois estimulam a observação e reflexão do aluno que passa a descobrir os fatos através dos documentos e não, exclusivamente, através do conhecimento fornecido pelo professor. Porém, alguns cuidados são essenciais, pois como dizem Rodrigues e Padrós:

A fragmentação, a pasteurização e a banalização da informação são características marcantes da pósmodernidade. A existência de uma superinformação sem reflexão coincide com a construção de um conhecimento fragmentado e desconectado da realidade com os atores sociais concretos (RODRIGUES; PADRÓS, 2000, p. 123).

\footnotetext{
${ }^{3}$ Maiores informações em Di Giovanni (1994, p. 27).

História \& Ensino, Londrina, v. 18, n. 2, p. 203-232, jul./dez. 2012
} 
A mídia, por exemplo, tem a pretensão de vender a sua verdade e de impô-la como única e histórica. Assim cabe ao professor mediar o registro do fato pela mídia e a sua compreensão enquanto conhecimento histórico.

Neves (1985, p. 6) cita uma série de características que podem estar presentes no ensino de História. Para a autora, a História deve ser: História-problema, ao invés da narrativa que tradicionalmente caracteriza a disciplina; História construída a partir do presente; História-reflexão, que indubitavelmente leva ao desenvolvimento crítico e, finalmente, Históriasíntese, que busca a capacitação das estruturas essenciais.

Para tanto, Neves (1985, p. 59-60) ressalta diferentes métodos que podem ser utilizados nas aulas de História. Considera importante trabalhar com grupos de discussão, pois "a criança tem o egocentrismo diminuído, com conseqüente aumento da cooperação". Outra alternativa sugerida é a ficha-síntese de texto, quando o pensamento do autor é traduzido pelo aluno para uma forma sintética. Acrescenta a autora:

sabemos da dificuldade de apreensão das idéias centrais que se faz presente na maior parte da população brasileira, incapaz de separar nitidamente o que é essencial do que é acessório. É obrigação da escola impedir tal condicionamento (NEVES, 1985, p. 66-67).

A criação de vocabulários históricos ilustrados, precedidos de desenhos feitos pelas crianças, é outra ideia ressaltada pela autora.

Para finalizar, acrescenta Neves (1985, p. 90): "Qualquer atividade lúdica é magnificamente aceita pelos alunos de qualquer faixa etária". Nesse sentido, vale apostar em alguns jogos didáticos que podem ser adaptados aos conteúdos de História, servindo como atividades atraentes e interessantes ao próprio desenvolvimento dos alunos. Simples jogos de cartas de baralho e de xadrez, por exemplo, dependendo da criatividade do professor e interação dos alunos, muito podem contribuir nas atividades do $6^{\circ}$ e $7^{\circ}$ anos do ensino fundamental.

Outra ideia interessante é a de Vasconcellos (1999). A autora propõe a substituição do livro didático por uma pasta elaborada e organizada pelos alunos. Isto seria possível, diz a autora, "a partir de pesquisa, com recortes 
de textos didáticos, jornais, revistas, fotografias, cartões postais, documentos históricos, entrevistas, mapas, etc." (VASCONCELLOS, 1999, p. 118). Para o aluno não ficar limitado ao livro didático também seria interessante realizar com os alunos um trabalho crítico com diversos livros didáticos.

Com bem destaca Fonseca (2005, p. 55-56), não é possível conduzir o ensino de História sem texto escrito. Assim, para abolir o livro didático nas aulas de História, o professor precisa organizar textos alternativos. 0 livro didático pode ser usado, mas não como uma fonte única de conhecimento histórico, tampouco com uma postura acrítica do conhecimento veiculado.

Complementando a ideia de Fonseca, diz Di Giovanni:

O texto escrito é material básico no processo ensinoaprendizagem da História. Cabe ao professor de História ensinar a ler História num caminho que, saltando da compreensão linear da "simples" tradução de vocábulo, passe para um aprofundamento da apreensão do significado do texto como um todo, levando o aluno a exercitar suas operações mentais e a descobrir o sentido e a intenção daquilo que ele lê (DI GIOVANI, 1994, p. 26).

O cinema também pode ser um recurso de que pode lançar mão o ensino de História. O professor pode utilizar filmes, por exemplo, como uma alternativa metodológica ao ensino de História, porém deve ter o cuidado de tratá-los, "não como portadores de verdades, mas sim como interpretação de uma realidade" (VASCONCELLOS, 1999, p. 118). A utilização de diferentes documentos pode facilitar o ensino de História, porém deve ficar claro para o aluno que um filme, uma canção, uma notícia de jornal, não representam a verdade absoluta, mas uma interpretação desta mesma realidade.

Enfim, cabe ao professor à tarefa de fazer do ensino-aprendizagem um convite para os alunos subverterem as fronteiras impostas entre as diferenças socioculturais.

Sair desse reprodutivismo excludente requer, além de enfrentar o falso conforto da menoridade intelectual, combater argumentos e práticas dos ideólogos neoliberal/conservadores, particularmente, a suposição de que professores e alunos são um vazio preenchido por ordens governamentais ou empresariais ao bel-prazer dessas autoridades. Nesses 
termos, a defesa inclui a consideração de escola e ensino enquanto espaços de disputa intelectual e política, evidenciando que aquele direito começa a ser exercido desde já (SILVA, 2000, p. 122).

Silva (2000) defende o direito a História, o que significa tanto para professores como para alunos e população em geral o direito ao conhecimento histórico, englobando o saber acumulado e o saber em produção.

Como destaca Fonseca (2005, p. 72), "não há educação e ensino sem professor, e o professor de história é uma pessoa que está na história, assim como a faz, sofre, desfruta e transforma". Porém, na lógica do "pensamento único"4 os professores são apenas transmissores secundários na escola que serve como depósito de seres durante uma etapa da vida considerada improdutiva. Os verdadeiros instrumentos educativos no "pensamento único" são as mídias eletrônicas. Assim, a escola e o ensino de História são vistos como anacrônicos. Isto porque, tanto a escola como o ensino de História tem o poder de promover o pensamento crítico, o que não é permitido na lógica do descarte, principalmente dos seres humanos.

Para impedir que o "pensamento único" alastre-se pelo campo da História, esterilizando debates e reflexões, são apresentadas, no subtítulo seguinte, as entrevistas com professoras de História. Busca-se, com isso, manter viva a pesquisa sobre o ensino de História, respondendo a algumas indagações sobre o ensino de História e, mais do que isso, proporcionando novos questionamentos que promovam o constante repensar desse mesmo ensino.

\section{Entrevistas com professoras de História: desvendando as múltiplas experiências e versões}

Na tentativa de manter a associação teoria/prática buscam-se novas informações sobre o ensino de História nos relatos de docentes da área. São

\footnotetext{
4 Segundo Ribeiro (2000, p. 141-142), atualmente, o Pensamento Único "está diretamente ligado às novas transformações da sociedade e à nova estruturação do capitalismo. A sua análise permite constatar que é a forma monolítica e dominante do pensamento conservador (naquilo que esse tem de pior)".
} 
apresentados trechos das entrevistas realizadas com quatro professoras de História da rede pública da cidade do Rio Grande (RS).

Destaca-se que as entrevistas foram baseadas na História Oral. Segundo Alberti (1989, p. 1), a História Oral, "[...] ora constitui método de investigação científica, ora fonte de pesquisa, ora ainda técnica de produção e tratamento de depoimentos gravados". Já Ferreira e Amado (1998, p. 16) consideram a História Oral como uma metodologia e não como uma técnica ou disciplina. Sendo assim, a História Oral

\begin{abstract}
apenas estabelece e ordena procedimentos de trabalho - tais como os diversos tipos de entrevista e as implicações de cada um deles para a pesquisa, as várias possibilidades de transcrição de depoimentos, suas vantagens e desvantagens, as diferentes maneiras de o historiador relacionar-se com seus entrevistados e as influências disso sobre seu trabalho funcionando como ponte entre teoria e prática (FERREIRA; AMADO, 1998, p. 16).
\end{abstract}

Tendo por base a ideia das autoras, as entrevistas foram gravadas e depois transcritas, obtendo-se um conjunto de relatos que constituem o objeto de análise. Para tanto, utilizou-se um roteiro geral de entrevista com questões que foram enfatizadas em todas as entrevistas.

Vale ressaltar que, neste trabalho apresenta-se um recorte do roteiro de entrevista, destacando três questões centrais. Na primeira questão os itens estão voltados para o conteúdo programático de História, mais especificadamente para os conteúdos do $6^{\circ}$ ano; os objetivos da escolha; os métodos utilizados; as expectativas do professor; o grau de dificuldade dos alunos; e, a relação entre a aprendizagem do aluno no $6^{\circ}$ ano com os anos seguintes. Esses itens pretendem revelar se realmente houve modificações no ensino de História, principalmente no que se refere aos conteúdos e métodos utilizados. A segunda questão refere-se aos recursos didáticos, sendo dividida em três itens: recursos disponíveis na escola, recursos utilizados e dificuldades encontradas. Como foi dito, uma aula diversificada, com recursos apropriados, pode colaborar para o envolvimento do aluno com a disciplina de História. Por isso, essa questão deve ser averiguada, na tentativa de manter ou encontrar novas formas de aprendizagem. Para finalizar a entrevista, optou-se por abrir um espaço de reflexão sobre a entrevista. Nesse momento as entrevistadas poderiam ressaltar algo 
importante e que colabore para o debate sobre o ensino de História. Com isso, abre-se a possibilidade para que seus questionamentos contribuam para a elaboração de novas pesquisas ${ }^{5}$.

A questão central da entrevista refere-se ao conteúdo programático de História no ensino fundamental. Essa questão revelou que a visão tradicional convive com uma nova perspectiva de História. Como bem destaca Gadotti (2000), a educação tradicional sobrevive até hoje, algumas práticas e teorias atravessam os tempos, mantendo a sua essência. Sendo assim, "tanto a concepção tradicional de educação quanto a nova, amplamente consolidadas, terão um lugar garantido na educação do futuro" (GADOTTI, 2000, p. 4).

Com o item sobre os conteúdos do $6^{\circ}$ ano, percebe-se que ainda há uma valorização excessiva do passado longínquo. Embora já tenham ocorrido muitas mudanças, as entrevistas confirmam que a periodização tradicional ainda está presente nos conteúdos de História. Esse problema está enraizado na estrutura curricular oficial das escolas que, segundo as professoras entrevistadas, pode sofrer algumas alterações, mas não pode ser completamente modificada.

Dessa forma, as turmas de $6^{\circ}$ ano das escolas pesquisadas estudam o período da História Antiga, destacando as principais civilizações, e o início da História Medieval que será aprofundada no $7^{\circ}$ ano e assim por diante, até se chegar a História Contemporânea. No entanto, como bem sugere Stephanou (1998, p. 38), o currículo precisa ser cortado, desmontado, decomposto "para que possamos compreender as formas particulares de conhecimento que ele contempla, as relações de poder que as sustentam, enfim os disciplinamentos do pensar, falar, sentir que impõe a todos nós, esta organização arbitrariamente constituída".

Ainda, percebe-se nas entrevistas que a lógica eurocêntrica mantémse no ensino de História. Isto porque no $6^{\circ}$ ano a Idade Antiga corresponde apenas à Antiguidade Clássica, restrita a alguns povos ao redor do Mar Mediterrâneo, excluindo as demais populações, como, por exemplo, da

\footnotetext{
5 Seguindo os passos da História Oral, ressalta-se que os relatos aqui apresentados, das entrevistas transcritas, foram autorizados pelas entrevistadas ao assinarem um termo de cedência das informações.
} 
América. Das quatro professoras entrevistas, apenas uma cita que trabalha com a "Pré-História geral e Pré-História do Brasil". Mas, nenhuma professora aborda a relação presente-passado no ensino de História que, como foi dito, poderia facilitar a aprendizagem do aluno.

É importante destacar que duas professoras ressaltam a importância de ensinar a introdução a História, conceitos e conhecimentos básicos para depois seguirem com os conteúdos da Idade Antiga. Já a introdução a Idade Média fica para o final do ano "quando dá um tempinho que é difícil. [...] Mas, a Idade Média é do $7^{\circ}$ ano", acrescenta a professora Maria Luiza (8 jul. 2008).

Como diz Bittencourt (2004, p. 213), "organizar os estudos de História por períodos é importante, mas depende das marcas de referência. Pode-se estabelecer novos critérios quando se criam novos temas e se pretende escapar do domínio da lógica eurocêntrica". Dessa forma, o grande desafio do professor está no fato de identificar outros agentes sociais e outros temas que não os privilegiados tradicionalmente.

Outro item trata dos objetivos da escolha do conteúdo. Essa questão reafirma o que foi dito acima, ou seja, busca-se seguir uma sequência cronológica, como se a História seguisse um processo evolutivo. Sabe-se que essa sequência dada ao conteúdo de História mantém-se até mesmo no ensino superior, portanto a intenção aqui não é de criticar o conteúdo programático do ensino fundamental. Até mesmo porque como diz Regina (5 maio 2008), "não é o professor que escolhe. Esse conteúdo vem da Secretaria de Educação", segue a professora, "até temos certa liberdade de mudar alguma coisa. Inclusive esse programa que temos aqui, nós professores de História daqui da escola - fizemos essa reformulação nele, porque tinham muitos conteúdos que não conseguíamos dar, então fomos pegando os principais". ${ }^{6}$

Apesar de tais justificativas, questiona-se: a sequência cronológica do conteúdo facilita ou dificulta a aprendizagem do aluno no ensino fundamental? Por um lado, pode-se pensar que o fato de que seguir uma sequência cronológica facilita a aprendizagem. É o caso das professoras

\footnotetext{
6 Apenas uma professora não confirmou que o conteúdo programático é sugerido pela Secretaria de Educação, dizendo que o conteúdo é estabelecido na escola onde trabalha. Porém, acrescenta-se que o conteúdo dessa escola não difere das demais.
} 
entrevistadas. Segundo a professora Maria Luiza (8 jul. 2008), torna-se "mais fácil eles [os alunos] entenderem este começo. Seguimos um padrão linear que, conforme vai passando o tempo, vamos trabalhando nas séries posteriores". Da mesma forma, a professora Regina (5 maio 2008) justifica a mudança do conteúdo no $6^{\circ}$ ano, da História do Brasil para História Antiga, dizendo: "[...] o objetivo era dar uma sequência para o aluno, porque se vamos pegar a História do Brasil, ela aparece lá no meio da História mundial. Então, resolveu-se começar com a História Antiga".

Por outro lado, acredita-se que a História quando muito distante da realidade do aluno pode não somente dificultar a aprendizagem como se tornar desinteressante por estar desvinculada da vida do aluno. Por isso, enfatiza-se novamente o quanto à relação presente-passado é fundamental no ensino de História. Acredita-se que por mais que o conteúdo trate de um passado remoto haverá sempre uma oportunidade de relacionar essa História com a realidade do aluno, mostrando semelhanças ou diferenças. No entanto, como bem acrescenta Nadai (1992, p. 28):

\begin{abstract}
Avançamos pouco, retrocedemos depois, temos ainda muita insegurança na organização de currículos e programas que possam ser direcionados para captar a historicidade do momento e estabelecer diálogos entre o saber escolar tradicional - a história institucional - e os saberes dessa população que adentrou a escola. É preciso, entretanto, continuarmos trabalhando, no sentido de ampliar o nosso conhecimento e nossa reflexão sobre a sua identidade como grupo e agente histórico.
\end{abstract}

O item seguinte do roteiro de entrevista refere-se aos métodos utilizados pelas professoras. A questão revela que as professoras buscam, quando possível, renovar as aulas. Diz Regina (5 maio 2008), "método específico eu não tenho. Trabalho muito com o livro didático que eles recebem e através do livro didático faço a exposição oral, com a participação deles quando tem interesse, perguntam". Já Maria Luiza (8 jul. 2008), diferenciando mais as atividades em sala de aula, responde: "[...] trabalho com o livro didático, [...] com reportagem, com outros livros. Utilizo outros livros na sala de aula com eles para poderem fazer uma comparação. Trabalho muito com resumos, aula expositiva, procuro trazer alguma coisa de material concreto para eles trabalharem". 
A professora Rosangela (7 maio 2008), mostrando uma proposta ainda mais renovadora nas aulas de História responde:

"Trabalho em grupo, de pesquisa. Vou procurar trazer [...] palestrantes porque como estou trabalhando com as religiões antigas e quero que eles tracem um paralelo com as religiões atuais. Eles escolheram três, no início do ano [...]. Então, vou trazer um palestrante [...] relacionado a cada uma delas [religiões] atuais e eles junto comigo, na aula, vão estudar as religiões antigas para depois traçarmos um paralelo no final do ano. $O$ que mudou? $O$ que tem de diferente? $O$ que a religião antiga trouxe para a atual? O que seguimos? $E$ isso, procurar fazer um tratado disso aí".

Ainda, para aprofundar o entendimento da expectativa dessa professora quanto às propostas de trabalho renovadoras, perguntou-se: $E$ a senhora percebe que os alunos aprendem mais assim, em uma aula diferenciada? Segue a professora Rosangela (7 maio 2008):

\begin{abstract}
"Aprendem. É difícil para colocar dentro do horário deles porque se vou trazer um palestrante mexo nas aulas dos outros professores. Agora mesmo havia um palestrante marcado, mas tive que desmarcar porque estava no período de provas. Trabalhar a interdisciplinaridade no papel é muito fácil, botar na prática é difícil em função do contexto da escola que ainda não trabalha como deveria".
\end{abstract}

Reafirma-se nessa resposta o quanto uma aula de História que fuja da rotina de nomes e datas pode despertar a curiosidade do aluno. Isso justifica a importância da disciplina de História na escola, pois ajuda a despertar o aluno para conhecer a atualidade. No entanto, como bem ressalta a professora Rosangela, ainda é difícil interligar teoria e prática, estabelecendo relação entre o conteúdo e a realidade social escolar. Isto porque, esclarece a mesma professora, o "contexto da escola [...] ainda não trabalha como deveria". Tal afirmação vai ao encontro do livro de Lück (2007). Segundo essa autora, o ensino encontra-se fragmentado, "eivado de polarizações competitivas, marcado pela territorialização de disciplinas, pela dissociação das mesmas em relação à realidade concreta, pela desumanização dos conteúdos fechados em racionalidades autosustentadas, pelo divórcio, enfim, entre vida plena e ensino" (LÜCK, 2007, p. 14). Por isso, ainda é difícil trabalhar a interdisciplinaridade, pois não existe um espaço de diálogo entre as disciplinas. 
O próximo item refere-se às expectativas do professor quanto à aprendizagem do aluno. Nesse momento da entrevista, cada uma das professoras ressalta o que considera importante na aprendizagem de História e o que gostaria que seus alunos carregassem para as séries seguintes.

A professora Rosangela (7 maio 2008) ressalta: "tenho uma expectativa que eles levem muita coisa. [...] não dou aula para eles no $7^{\circ}$ ano, mas, como digo para eles: [...] 'vocês têm que procurar entender isso aqui'. Porque entro em Idade Média e a [outra] professora continua no $7^{\circ}$ ano". Já a professora Regina enfatizou o que considera importante na aprendizagem de História, mostrando-se atualizada com a nova abordagem para o ensino de História que busca acabar com a ideia de que a História é uma disciplina para ser decorada. Relata a professora Regina (5 maio 2008):

\begin{abstract}
"[...] o aluno tem muita preocupação em decorar a História. Digo para eles: "História é uma história" [...] não precisa gravar datas. Não peço datas para eles em provas. [...] Precisamos é só ter uma ideia de quando aquilo ocorreu e saber contar o fato até com as próprias palavras. Eles não precisam seguir as linhas, nem aquilo que está escrito no livro. E nessas civilizações antigas procuro ressaltar o que teve de contribuição desses povos para nossos dias. Porque temos muita coisa do nosso dia-a-dia, na nossa vida, que são contribuições dos povos antigos".
\end{abstract}

A professora Eliane (15 maio 2008) também apresenta um relato interessante. Diz: "Eles no início sempre perguntam: 'Mas, para que estudar tudo isso?' [...] Sempre digo para eles: [...] 'quem somos nós?' Então, temos que saber a nossa História para depois seguir a vida, para não errar ou então para melhorar". Segue a professora: "Então, a minha expectativa com eles, pode ter certeza, é a das melhores". Essa pergunta da professora para os alunos, logo no início do ano, certamente é bastante esclarecedora. Entender o motivo de estudar a História poderia ser o primeiro passo do aluno para o seu envolvimento com a disciplina.

Por fim, é importante destacar o relato da professora Maria Luiza. Sempre mostrando espontaneidade nas suas respostas, essa professora não 
deixou de destacar alguns pontos negativos, quando esses se mostravam necessários, ao longo da entrevista. Diz Maria Luiza (8 jul. 2008):

"[...] vou ser bem sincera, a resposta não tem sido o que esperamos. Então, tenho observado que cada vez diminuo o nível de exigência porque eles leem pouco, então dão uma resposta muito menor do que aquilo que esperamos. Então, cada vez tenho diminuído mais a exigência deles. A expectativa não tem sido das melhores".

Para compreender os motivos de algumas defasagens ou facilidades de aprendizagem optou-se por acrescentar mais uma pergunta na entrevista que não se encontra no roteiro. A pergunta foi a seguinte: Os alunos trazem ou não uma bagagem das séries iniciais para a disciplina de História no $6^{\circ}$ ano? As professoras destacam que nas séries iniciais 0 conteúdo é completamente diferente do estudado no $6^{\circ}$ ano. Como diz uma professora, "muito pouco [conhecimento], até porque é estanque. Estão lá em História do Rio Grande do Sul nos anos iniciais e chegam aqui vendo as primeiras civilizações no $6^{\circ}$ ano [riso]". Confirma-se nesse momento o que dizem Nadai e Bittencourt (1992, p. 75), ou seja, o saber histórico nas séries iniciais é meramente introdutório e sem vinculação com as séries sequenciais. Dessa forma, reafirma-se a necessidade de desenvolver um conhecimento básico nas séries iniciais para que uma aprendizagem significativa possa fluir nas séries seguintes. ${ }^{7}$

Outra professora diz: "Pouco, pouco. Essa parte de História Antiga muito pouco, até porque no currículo eles trabalham muito com História da cidade e História do Rio Grande do Su. Então, essa parte da História [Antiga] eles não veem quase nada". Segue a professora: "É novidade. $O$ que sabem, a base que eles têm, é o que eles escutaram falar, viram na televisão ou alguma coisa assim. Alguns, às vezes, têm um interesse maior, então conhecem um pouquinho mais alguma coisa. Mas, é pouquíssimo conhecimento que eles têm".

Como uma das professoras destacam, "o que sabem, a base que eles têm, é o que eles escutaram falar, viram na televisão ou alguma coisa

\footnotetext{
7 Tal necessidade foi ressaltada por Campos (2000, p. 135-141) que destacou, com base em pesquisa realizada nas escolas públicas da cidade do Rio Grande, alguns relatos de professoras de História que ressaltam problemas ainda vigentes na prática pedagógica. Sendo o maior obstáculo, o contraste entre os conteúdos dos anos iniciais, referentes à História do Rio Grande do Sul, e do $6^{\circ}$ ano, com conteúdos de História Antiga.
} 
assim". Essa resposta também faz pensar na importância de explorar os recursos didáticos para facilitar a aprendizagem, já que a base do conhecimento de História dos alunos no $6^{\circ}$ ano é adquirida, principalmente fora dos muros da escola. É o que confirma também a professora Regina ( 5 maio 2008), ao dizer que na escola a sala de computadores ainda não foi utilizada, "agora, em casa, percebo, eles usam bastante".

Seguindo o roteiro de entrevista, outro item esclarece sobre o grau de dificuldade dos alunos. Todas as professoras entrevistadas responderam que os alunos têm uma dificuldade inicial de adaptação no $6^{\circ}$ ano. Isso porque até o $5^{\circ}$ ano os alunos têm apenas um professor. A partir do $6^{\circ}$ ano surgem outros professores que apresentam propostas de trabalho diferenciadas. Então, essa diferenciação causa uma dificuldade de adaptação e organização que também está associada à idade dos alunos. É o que expressa à professora Maria Luiza (8 jul. 2008):

\footnotetext{
"Vejo que eles são bastante dependentes da ajuda do professor. Na questão da organização de material, da organização de entrega de trabalhos eles demonstram certa dificuldade. Aquela coisa bem inocente, assim: "professora tinham três trabalhos para fazer, não consegui". Porque não conseguem se organizar. Esse início, até a metade do ano, eles fazem essa confusão. Depois, claro, vou botando uma pressão para irem entrando no ritmo, mas tem essa coisa da dependência. A própria idade colabora para isso, para que eles sejam dependentes".
}

Ainda, o mesmo item reafirma um tema ressaltado anteriormente quando se destaca a importância da realização de um teste de sondagem para avaliar o nível de aprendizagem dos alunos. Essa avaliação é fundamental, pois o professor precisa saber que bases de aprendizagem foram construídas nas séries anteriores. Essa sondagem foi realizada pela professora Regina que constatou algumas defasagens de aprendizagem enfrentadas pelos alunos no $6^{\circ}$ ano. Enfatiza Regina (5 maio 2008):

"Acho que o nosso aluno do $6^{\circ}$ ano vem muito despreparado
do currículo, do $1^{\circ}$ ao $5^{\circ}$ anos. Acho que, por ser uma
professora só que trabalha com eles, a tarde toda, existe
certa proteção. [...] Dificuldade de leitura e interpretação é
um horror. Pedes para o aluno ler um parágrafo, ele gagueja
o tempo inteiro que nem sei como consegue entender o que 
está lendo. Porque eles vêm com uma série de dificuldade do currículo".

A questão referente à relação entre a aprendizagem do aluno no $6^{\circ}$ ano com os demais anos, complementou o item anterior. Nos relatos, as professoras afirmam que a dificuldade maior do aluno é no $6^{\circ}$ ano, devido à "organização, adaptação e mais a idade mesmo", resume a professora Eliane (15 maio 2008). Ainda, as professoras acrescentam que $08^{\circ}$ ano também apresenta alguns problemas, embora sejam esses problemas diferentes dos apresentados no $6^{\circ}$ ano. É o que diz, por exemplo, a professora Eliane (15 maio 2008):

Eles sentem dificuldade, todo o aluno do Fundamental, é no $6^{\circ}$ ano e no $8^{\circ}$ ano. Não sei o porquê, mas acredito que no $6^{\circ}$ ano é a mudança de professores. Agora, no $8^{\circ}$ ano não sei por que eles têm essa dificuldade. Acho que é a adolescência, o pico da adolescência, deve ser [risos].

Por tudo que foi relatado, ressalta-se novamente o quanto 0 conhecimento tanto dos trabalhos embasados na teoria de Piaget como de Vygotsky poderiam ajudar o professor a desenvolver seu trabalho, entendendo melhor o comportamento dos alunos. Para tanto, por exemplo, o professor poderia levar em consideração a fase de transição do período das operações concretas, entre 7 a 11 ou 12 anos, para as operações abstratas, 11 ou 12 anos em diante. Sendo essa, no entanto, uma referência e não uma norma rígida. Ainda, apoiando-se na teoria de Vygotsky deveria considerar a origem social da capacidade intelectual dos alunos, levando em consideração a importância da interação social para o desenvolvimento de novas e mais complexas funções mentais. Esses embasamentos certamente esclareceriam algumas dúvidas relacionadas à adaptação, organização e comportamento dos alunos em sala de aula.

Para finalizar essa questão, ressalta-se outro relato importante da professora Maria Luiza. Segundo ela, os problemas enfrentados no $6^{\circ}$ ano são superados nos anos seguintes por aqueles alunos que têm um apoio familiar. Já aqueles alunos que têm pais omissos, acabam carregando as dificuldades nas séries seguintes. Diz a professora Maria Luiza (8 jul. 2008):

Então, aqueles alunos que têm um histórico escolar de apoio da família, que a família trabalha junto com a escola, depois 
nos outros anos esses problemas vão sendo superados. No $7^{\circ}$ ano eles já estão mais maduros. Então, já tiveram todo um acompanhamento no $6^{\circ}$ ano. Nos anos seguintes conseguem ir superando essas coisas. Agora, aqueles alunos que vêm com desestrutura familiar, eles vão carregando isso para todos os anos. Então, [...] vou trabalhando em cima da maturidade deles porque no $7^{\circ}$ e $8^{\circ}$ anos eles são mais velhos. Mas, aonde tem uma desestrutura familiar encontro maior dificuldade para fazer com que se organizem.

A sensibilidade dessa professora para questões relacionadas a desestrutura familiar que afeta a aprendizagem, certamente, favorece a sua aproximação com os seus alunos e contribui para o envolvimento desses alunos com o ensino de História. Como bem expressam Anami e Lima (2004, p. 99), o educador deve conhecer o desenvolvimento emocional dos seus alunos, pois "a emoção bloqueia ou abre os canais para que se efetive o conhecimento". Portanto, o educador que não se "alfabetizar" emocionalmente terá dificuldades para atingir seus objetivos com os alunos. Isso, no entanto, não parece ser o caso da professora Maria Luiza.

O próximo tema refere-se aos recursos didáticos, sendo dividido em três itens. No item sobre os recursos disponíveis na escola, o que foi mais destacado foi a biblioteca, sendo que na rede estadual as bibliotecas não funcionam diariamente, pois não tem bibliotecária. As professoras da rede municipal destacam somente a biblioteca e o laboratório de informática que, porém ainda não foi utilizado. Destaca a professora Regina (5 maio 2008), "temos a biblioteca que é bem boa. Podemos utilizar a biblioteca, levar os alunos para trabalhar ou pedir um trabalho extra". Já as professoras da rede estadual, destacam além da biblioteca, os recursos audiovisuais e o laboratório de informática que, porém está sendo montado ou é utilizado por poucos alunos e professores.

Quanto aos recursos utilizados, segundo as professoras eles estão de acordo com os disponíveis na escola. Desses recursos foram destacados os livros didáticos, mapas, filmes e músicas. A importância da utilização de recursos diversificados já foi citada, pois se acredita que essa diversificação de recursos pode facilitar a aprendizagem e ajudar o aluno a envolver-se com as questões históricas. 
O último item da questão sobre os recursos didáticos refere-se às dificuldades encontradas. Nesse momento as professoras destacam, principalmente, a falta de recursos materiais e humanos, além da pouca carga horária da disciplina. A professora Eliane (15 maio 2008), por exemplo, ressalta que a única maneira de superar as dificuldades é trocando de material com outros professores. Já a professora Maria Luiza (8 jul. 2008) vai mais além, destacando:

"Como tenho só duas aulas com eles por semana é uma correria para ir procurar o recurso, usar, carregar. Então, se preciso usar, por exemplo, o retroprojetor: tenho que chegar antes na escola, pegar o retroprojetor, procurar a extensão, levar para sala, ligar, desligar. Entendeu? É tudo comigo, então realmente fica bastante corrido. Agora com o laboratório de informática, aí ficas pensando: tenho que levar a minha turma, primeiro que vamos ter poucos computadores com turmas bastante grandes; e depois vou ter que chegar no laboratório e ligar os computadores. [...] vou ter que lidar com essas duas coisas: com cuidar dos alunos, controlar os alunos ali, e controlar a parte material que é difícil. Faço, mas é difícil. O que tenho mais sentido falta, então agora são os recursos humanos. São os apoios que precisamos".

Enfim, chega-se à última questão da entrevista. O espaço de reflexão permite que as professoras destaquem algo considerado importante ou que não foi abordado. Esse momento foi importante, pois as professoras mostraram-se envolvidas com a entrevista, colaborando com questões que as afligem enquanto educadoras ou mostrando satisfação por participar da pesquisa.

A professora Rosangela (7 maio 2008) destacou a dificuldade que carrega desde a sua formação em elaborar projetos de ensino. Embora realize um trabalho inovador com os alunos, a professora não sabe "colocar ele no papel como gostaria", como ela mesma destaca. Dessa forma, não pode utilizá-lo no ano seguinte para ir aprimorando os seus trabalhos. Ainda, acrescenta a professora "se o Alzheimer chegar aqui [aponta para a cabeça] acaba tudo. Entendesse? [risos]". Tais colocações abrem espaço para um debate sobre a necessidade de cursos de formação continuada ou de uma aproximação escola-universidade. Isso para que os professores nos ensinos fundamental e médio possam se atualizar e sanar suas dificuldades, aprimorando a prática pedagógica. Até porque, como bem expressa Lima 
(2004, p. 36), "a modernidade exige mudanças, adaptações, atualização e aperfeiçoamento. Quem não se atualiza fica para trás".

A professora Maria Luiza (8 jul. 2008) também utilizou o espaço para falar sobre sua experiência e destacar a importância da pesquisa no curso de História. Dessa forma, relata as conversas dos professores sobre a situação atual da educação, a falta do apoio familiar e a desvalorização do professor associado à questão salarial. Lima expressa bem o que a professora Maria Luiza transmitiu no seu relato, ou seja:

[...] ou se investe no professor, em sua formação, atualização e satisfação pessoal e profissional, ou a escola continuará sendo a mentira que é: de portas abertas, sim, porém, um pseudo-ensino, sem características de eqüidade, ultrapassada, a serviço da manutenção do status quo, que é o que deseja a classe dominante (LIMA, 2004, p. 36).

Para finalizar, destaca-se a fala da professora Eliane. Tal relato, assim como os demais, confirma a importância da pesquisa para ressaltar a história desses profissionais que mesmo sendo, muitas vezes, desvalorizados, sentem-se gratificados pela sua profissão. Diz a professora Eliane (15 maio 2008):

Sabe que é a primeira vez nesses 17 anos de magistério que tenho [...] que me fazem assim [uma entrevista]. Fiquei encantada, com certeza, achei interessante poder falar um pouco do meu trabalho. Entendesse? E dizer para vocês, que estão iniciando, que mesmo com a falta de salário que temos, mesmo com a falta de recursos [...] adoro aquilo que faço. Sabe? Não me arrependo em nenhum momento de ter começado o magistério e ter começado na escola pública que é um trabalho muito gratificante.

Enfim, inúmeros aspectos estão em jogo e contribuem para criar a situação adversa onde se dá a prática educativa. As entrevistas com as professoras de História deixam evidentes: a falta de recursos didáticopedagógicos e até mesmo de recursos humanos, o aviltamento salarial e o desprestígio da profissão. Portanto, torna-se fundamental a reflexão sobre as condições precárias da educação pública e, ainda a busca por uma prática pedagógica que favoreça a apropriação do saber por parte dos educandos. 


\section{Considerações finais}

As entrevistas com as quatro professoras de História confirmam que os alunos têm uma dificuldade maior no $6^{\circ}$ ano. Essa dificuldade, segundo as professoras, está associada à adaptação e organização iniciais, além da idade dos alunos. Por isso, acredita-se que a aprendizagem está associada ao desenvolvimento mental e social dos alunos. Esse conhecimento pode ajudar o professor a desenvolver melhor o seu trabalho, entendendo melhor o comportamento dos alunos na sala de aula.

Ainda, a pesquisa também revela que apesar das modificações ocorridas no ensino de História, ao longo de várias décadas, muito do ensino tradicional ainda está presente, principalmente no que se refere à seleção dos conteúdos. Isto porque o sistema educacional ainda não rompeu com a periodização tradicional dos conteúdos de História. Dessa forma, $06^{\circ}$ ano prende-se a História Antiga, a um passado remoto, desvinculado da vida dos alunos e, portanto desinteressante. Porém, acredita-se que com um pouco de iniciativa e criatividade o professor pode unir os fios do passado aos do presente, não vendo o conteúdo oficial como uma camisa de força.

Enfim, acredita-se que as entrevistas deixaram mais do simples relatos, nelas encontram-se ensinamentos e mensagens a todos aqueles que ousam participar dessa História e encontrar nela a sua vida. Mesmo não conseguindo resolver os problemas que envolvem o ensino de História, fica aqui o convite para que se mantenham as reflexões propostas nesse trabalho. Até mesmo porque a permanente reflexão abre perspectivas para a transformação, na tentativa de encontrar alternativas para a situação vigente.

\section{Referências Bibliográficas}

ALBERTI, V. História oral: a experiência do Cpdoc. Rio de Janeiro: Fundação Getúlio Vargas, 1989.

ANAMI, D. C.; LIMA, V. S. de. Formação de professores: revendo a prática da didática e dos estágios. In: PONTES, A. (Org.). Educação e formação de professores: reflexões e tendências atuais. São Paulo: Zouk, 2004, p. 97106. 
BERGAMASCHI, M. A. Tempo e memória: o que se ensina na escola? In: LENSKIJ, Tatiana; HELFER, N. E. (Org.). A memória e o ensino de História. Santa Cruz do Sul: Edunisc; São Leopoldo: ANPUH/RS, 2000, p. 39-51.

BITTENCOURT, C. M. F. Ensino de história: fundamentos e métodos. São Paulo: Cortez, 2004.

BOCK, Ana. Uma introdução ao estudo de Psicologia. 13. ed. São Paulo: Saraiva, 2002.

CALLAI, Helena (Org.). O ensino em Estudos Sociais. Ijuí: UNIJUÍ, 1991.

CAMPOS, D. A. A História e a prática pedagógica. In: ALVES, Francisco das Neves; TORRES, L. H. (Org.). Anais do IX Ciclo de Conferências Históricas. Rio Grande: Fundação Universidade do Rio Grande, 2000, p. 135-141.

CARRETERO, M. Construir e ensinar: as ciências sociais e a história. Porto Alegre: Artes Médicas, 1997.

DI GIOVANNI, M. L. História. São Paulo: Cortez, 1994.

ENDERLE, C. Psicologia do desenvolvimento: o processo evolutivo da criança. Porto Alegre: Artes Médicas, 1985.

FERREIRA, M.; AMADO, J. (Coord.). Usos e abusos da História Oral. Rio de Janeiro: Fundação Getúlio Vargas, 1998.

FONSECA, S. G. Didática e prática de ensino de História. 4. ed. Campinas: Papirus, 2005.

FUNARI, P. P. A renovação da História Antiga. In: KARNAL, L. (Org.). História na sala de aula: conceitos, práticas e propostas. 5. ed. São Paulo: Contexto, 2007, p. 95-107.

GADOTTI, M. Perspectivas atuais da educação. São Paulo Perspect., São Paulo, v. 14, n. 2, p. 3-11, 2000. Disponível em:

<www.scielo.br/pdf/spp/v14n2/9782.pdf> Acesso em: 20 mar. 2008.

LIMA, V. S. de. Considerações sobre a formação continuada de educadores. In: PONTES, A. (Org.). Educação e formação de professores: reflexões e tendências atuais. São Paulo: Zouk, 2004, p. 35-42.

LÜCK, H. Pedagogia interdisciplinar: fundamentos teórico-metodológicos. 15. ed. Rio de Janeiro: Vozes, 2007.

MICELI, P. Por outras histórias do Brasil. In: PINSKY, Jaime (Org.). O ensino de História e a criação do fato. 4. ed. São Paulo: Contexto, 1992, p. 31-42.

MIZUKAMI, M. da G. N. Ensino: as abordagens do processo. São Paulo: EPU, 1986.

NADAI, E. O ensino de História e a "Pedagogia do Cidadão". In: PINSKY, Jaime (Org.). O ensino de História e a criação do fato. 4. ed. São Paulo: Contexto, 1992, p. 23-29.

BITTENCOURT, C. M. F. Repensando a noção de tempo histórico no ensino. In: PINSKY, J. (Org.). O ensino de História e a criação do fato. 4. ed. São Paulo: Contexto, 1992, p. 73-92. 
NEVES, M. A. M. Ensinando e aprendendo História. São Paulo: EPU, 1985.

NIDELCOFF, M. T. A escola e a compreensão da realidade. São Paulo:

Editora brasiliense, 1993.

PENTEADO, H. D. Metodologia do ensino de História e Geografia. São Paulo: Cortez Editora, 1991.

RIBEIRO, L. D. T. História e Pensamento Único. In: LENSKIJ, Tatiana; HELFER, Nadir Emma (Org.). A memória e o ensino de História. Santa Cruz do Sul: Edunisc; São Leopoldo: ANPUH/RS, 2000, p. 141-150.

RODRIGUES, G.; PADRÓS, E. S. História imediata e pensamento único: reflexões sobre a História e o ensino de História. In: LENSKIJ, T.; HELFER, N. E. (Org.). A memória e o ensino de História. Santa Cruz do Sul: Edunisc; São Leopoldo: ANPUH/RS, 2000, p. 123-139.

SILVA, Marcos A. da. Ensino de História, exclusão social e cidadania cultural - contra o horror pedagógico. In: LENSKIJ, T.; HELFER, N. E. (Org.). A memória e o ensino de História. Santa Cruz do Sul: Edunisc; São Leopoldo: ANPUH/RS, 2000, p. 109-122.

STEPHANOU, M. Instaurando maneiras de ser, conhecer e interpretar. Rev. Bras. Hist., São Paulo, v. 18, n. 36, p. 15-38, 1998.

VASCONCELLOS, M. M. M. Ensino de História: concepção e prática no ensino médio. In: BERBEL, Neusi Aparecida Navas. Metodologia da problematização: fundamentos e aplicações. Londrina: Ed. UEL, 1999, p. 101-149.

\section{Entrevistas}

COSTA, Rosangela Meireles. Entrevista concedida a Josiane Alves da Silveira. Rio Grande, 7 maio 2008.

FERREIRA, Maria Luiza Tavares. Entrevista concedida a Josiane Alves da Silveira. Rio Grande, 8 jul. 2008.

NEVES, Regina Quiroga. Entrevista concedida a Josiane Alves da Silveira. Rio Grande, 5 maio 2008.

ROSA, Eliane Fialho. Entrevista concedida a Josiane Alves da Silveira. Rio Grande, 15 maio 2008.

Recebido em 24 de agosto de 2012. Aprovado em 17 de dezembro de 2012. 